University of Nebraska - Lincoln

DigitalCommons@University of Nebraska - Lincoln

Winter 12-3-2019

Installation Process of Radio Frequency Identification System in Libraries: A Case Study on Assam Don Bosco University Library

Dr. Anupam Chanda

Assam Don Bosco University, anupamchnd1988@gmail.com

Follow this and additional works at: https://digitalcommons.unl.edu/libphilprac

Part of the Library and Information Science Commons

Chanda, Dr. Anupam, "Installation Process of Radio Frequency Identification System in Libraries: A Case Study on Assam Don Bosco University Library" (2019). Library Philosophy and Practice (e-journal). 3718. https://digitalcommons.unl.edu/libphilprac/3718 


\title{
Installation Process of Radio Frequency Identification System in Libraries: A Case Study on Assam Don Bosco University Library
}

\author{
Dr. Anupam Chanda \\ Librarian, Assam Don Bosco University, Guwahati, Assam, India-781017 \\ Email; anupamchnd1988@gmail.com
}

\begin{abstract}
Radio Frequency Identification in short RFID belongs to technology referred to as Automatic Identification and Data Capture (AIDC). The RFID tag operates at $13.56 \mathrm{MHz}$, and the tag contains a microchip and an antenna. RFID readers can read multiple RFID tags instantaneously at near-proximity through radio wave. RFID helps to save time with maximum accuracy in the circulation counter. Stock verification through RFID system can be done efficiently and accurately, with the help of RFID handheld reader. Theft detection is one of the most valuable features of RFID system.
\end{abstract}

Assam Don Bosco University presently has two campuses. Both the campuses has its individual library system. RFID system has been installed in both the campus libraries. The paper discusses the whole process of the installation of RFID system and its benefits in the library. The researcher has also given some suggestions which can be considered before going for RFID installation in the library.

Keywords: RFID system, ADBU, Web-OPAC.

\section{INTRODUCTION}

Radio Frequency Identification (RFID) has come a long way to provide basic components to create a degree of automation in libraries. RFID system allows item identification in addition to item security in the library. The RFID tag operates at $13.56 \mathrm{MHz}$, and the tag contains a microchip 
and an antenna. The RFID tag which is attached to books or library materials are programmed with identification and security information. RFID readers can read multiple RFID tags instantaneously at near-proximity through radio wave; therefore, check-in, check-out and materials handling tasks are quicker and more comfortable for both library users and staff.

Libraries who are intensive on reducing staff time needed for materials handling, streamline high circulation activities, focused on inventory and collection management solutions can use RFID system. There are many advantages of RFID system revolve around the actual use of the technology in libraries to free up library staffs for duties that involve more interaction with the patrons.

\section{Objectives of the study}

- To know about the installation process of RFID system in the library;

- To understand the benefits of RFID system in the library;

- To provide suggestions to the librarians about the RFID system.

\section{LITERATURE REVIEW}

Erwin and Kern (2005) surveyed on RFID in libraries, where they mentioned that the RFID systems have been in use in libraries for many years to identify the library materials, self-checkin/out, theft detection, inventory control, and for the sorting and conveying of library books and AV materials. RFID in the library can lead to significant savings in staff costs, enhance service, lower book theft. The mechanical features of a modern RFID system are described to provide a guideline for the assessment of different systems.

Singh and Mahajan (2014) wrote an article on the components and technical features of a modern RFID library system, its advantages and issues related to the use of RFID in libraries. 
Their paper also discusses the present status of RFID implantation in Indian libraries and give some suggestions for implementing RFID in libraries.

Pal and Sharma (2017) conducted a survey on the implementation of RFID technology in libraries, where they found several challenges and obstacles to RFID adoption, as well as emerging technologies relevant to RFID. They also describe the potential of RFID technology in simplifying resourceful library maneuvers and demonstrates that RFID can be used in libraries to ensure security and facilitate advanced services and highlights key issues that need to be spoken in order to accomplish the successful implementation of RFID in libraries and also examines key challenges in the deployment of the technology.

\section{ABOUT ASSAM DON BOSCO UNIVERSITY (ADBU) LIBRARY}

Assam Don Bosco University was officially inaugurated by Shri Tarun Gogoi, the then Chief Minister of Assam, on 6th December 2008, after that the Rector Major of Don Bosco Society Fr. Pascual Chavez visited India in 2009, the blessing of the foundation stone of the university was held on 10 November 2009 at the Azara campus. Assam Don Bosco University presently has two campuses one is Don Bosco College of Engineering and Technology, Azara campus, Airport Road, Azara, Guwahati and other is Assam Don Bosco University Main campus at Tapesia Gardens, Kamarkuchi, Sonapur, Guwahati. The library of Assam Don Bosco University was established in the year 2009 at Azara campus and in the year 2016 in Tapesia campus of Assam Don Bosco University. Both the libraries has started its automation with Koha inter library management software in their respective year of establishment. 
Library resources in ADBU (upto Nov, 2019)

\begin{tabular}{|c|c|c|}
\hline Particulars & Azara Campus Library & Tapesia Campus Library \\
\hline Text books & $17000+$ & $6500+$ \\
\hline Reference books & $500+$ & $100+$ \\
\hline e-Books/e-Teaching tools & 9 & NA \\
\hline Journals & $75+$ & $5+$ \\
\hline e-Journals & \multicolumn{2}{|c|}{764} \\
\hline Digital database (subscribed) & \multicolumn{2}{|l|}{2} \\
\hline CD \& Video & $890+$ & $70+$ \\
\hline Library automation year & 2009 & 2016 \\
\hline Automation status & \multicolumn{2}{|c|}{ Fully automated with Koha ILMS and RFID system (2019 } \\
\hline Weeding out books & $500+$ & NA \\
\hline Magazines & $22+$ & $7+$ \\
\hline Newspapers & 6 & 5 \\
\hline Project reports & $350+$ & $400+$ \\
\hline Thesis & $20+$ & $18+$ \\
\hline
\end{tabular}

Table 1: Details of library resources 


\section{Library services in ADBU library}

- Inter-Library Loan (On request);

- Reference services;

- Circulation with RFID system;

- Web-OPAC facility;

- Internet access;

- Previous year question paper access;

- Library orientation;

- Access facility to various subscribed and free e-resources;

- Book exhibition;

- Purchase suggestions;

- Volunteer work;

- Anti-Plagiarism checking services;

- Library mobile Android App (ADBU App);

- Previous year project report access service;

- New arrivals display services.

\section{Centralized library}

All the two campus libraries are connected with a single server, the ILMS and IR software are installed in the server which is placed at ADBU Azara campus and can be accessed from all the two campuses via internet. From Azara campus it can also be accessible through LAN. Students, faculty and staffs can access the library resources through Web-OPAC from anywhere whether they are in off-campus or on-campus 


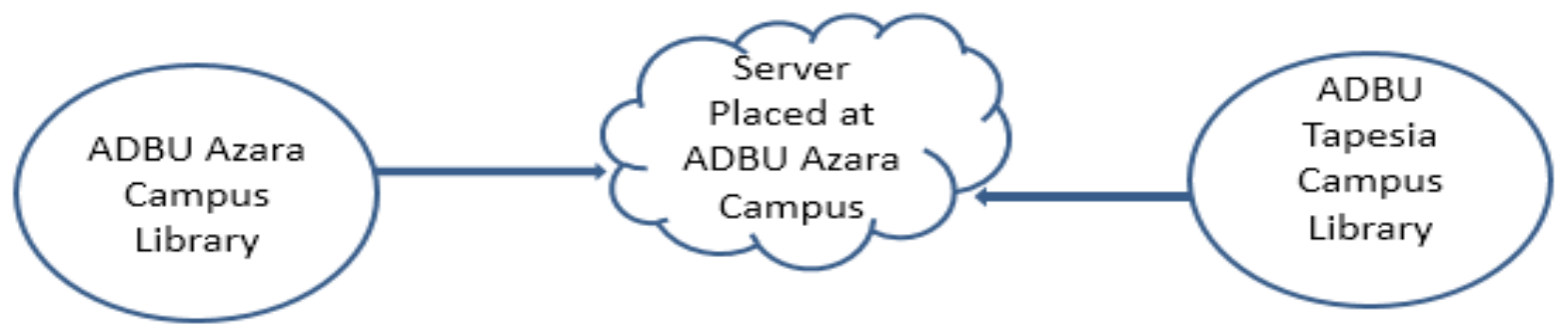

Fig 1: Centralized library system

\section{ABOUT RFID SYSTEM}

Radio-Frequency Identification mostly known as RFID refers to a technology whereby a reader captures digital data encoded in RFID tags or smart labels via radio waves, it is one of the most advanced technology now a day's. RFID belongs to technology referred to as Automatic Identification and Data Capture (AIDC). RFID methods apply radio waves to complete this. RFID systems consist of mainly three components, RFID tag or smart label, RFID reader, and an antenna. RFID tags contain an incorporated circuit and an antenna, which are used to communicate data to the RFID reader. The reader then transforms the radio waves to a more operational form of data. Information collected from the tags is then transported through a communications interface to the server, where the data can be stored in a database and evaluated at a later time.

\section{Components of RFID system in the ADBU library}

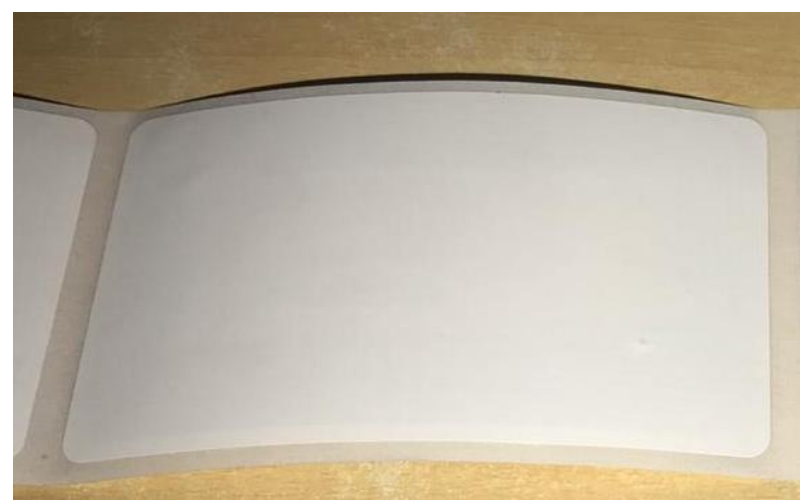

Fig 2: RFID tag

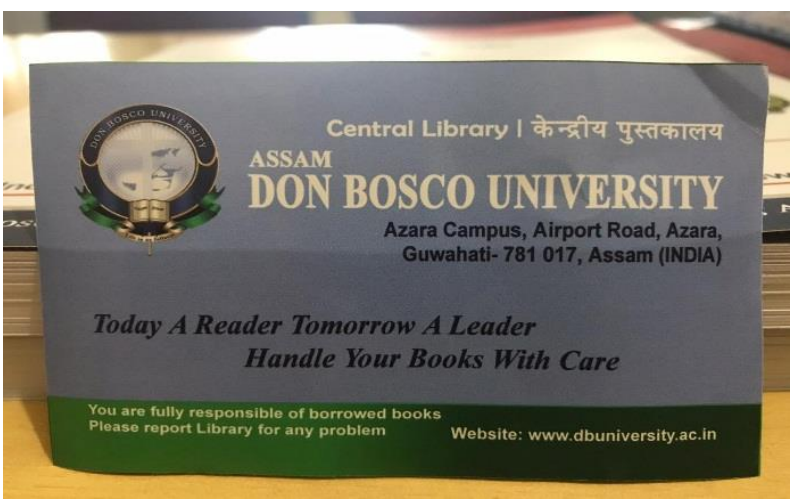

Fig 3: Sticker 


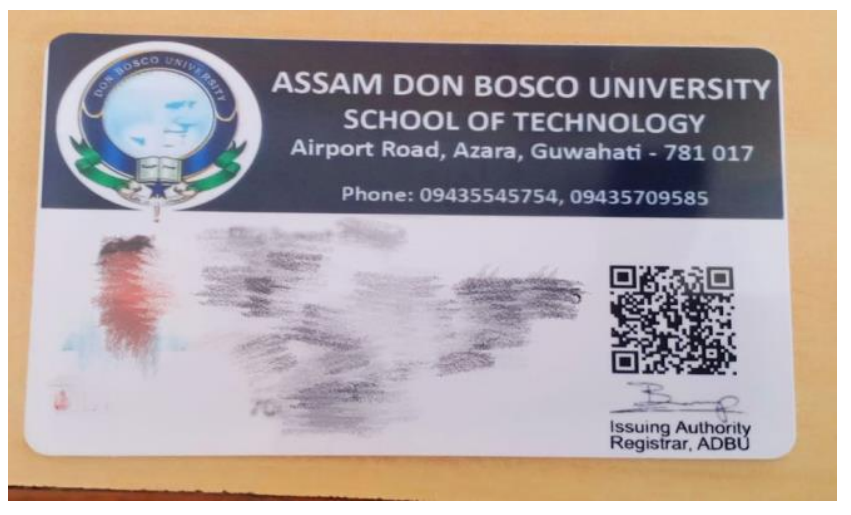

Fig 4: RFID smart card

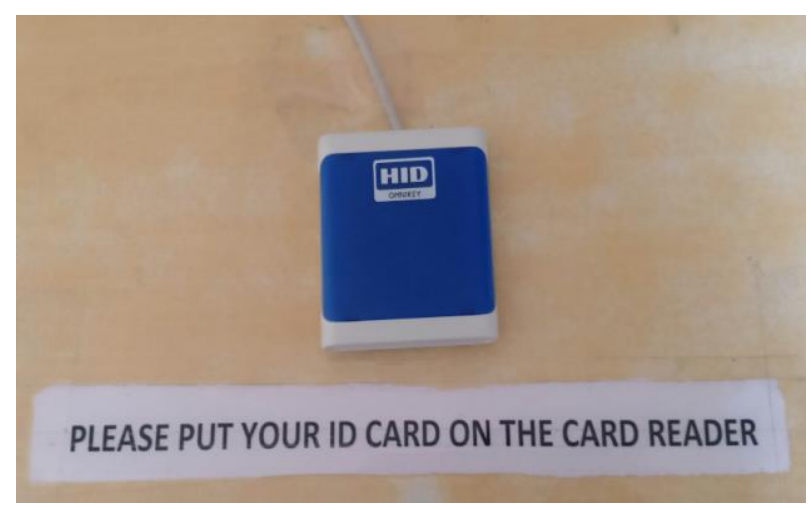

Fig 6: RFID smart card reader

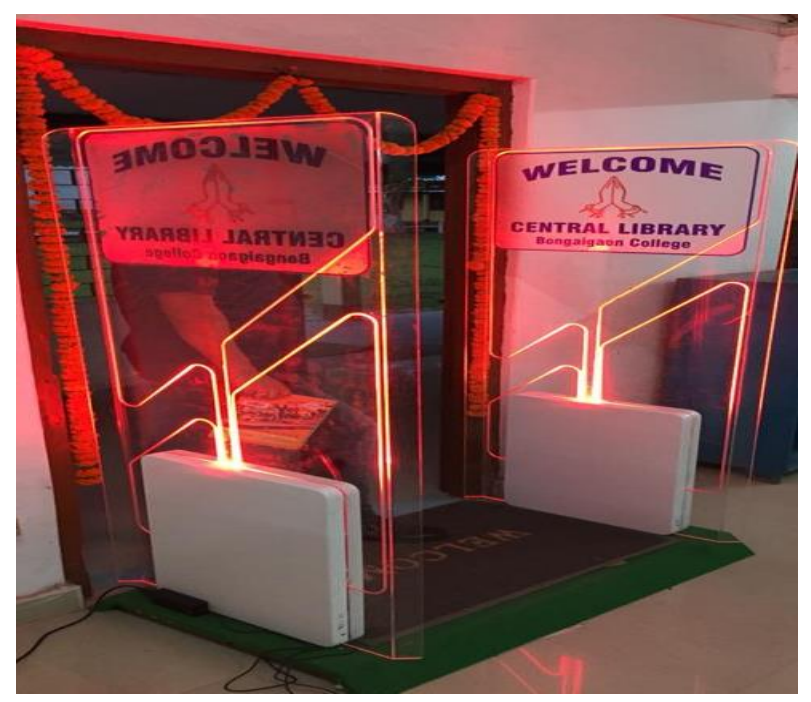

Fig 8: RFID security gate

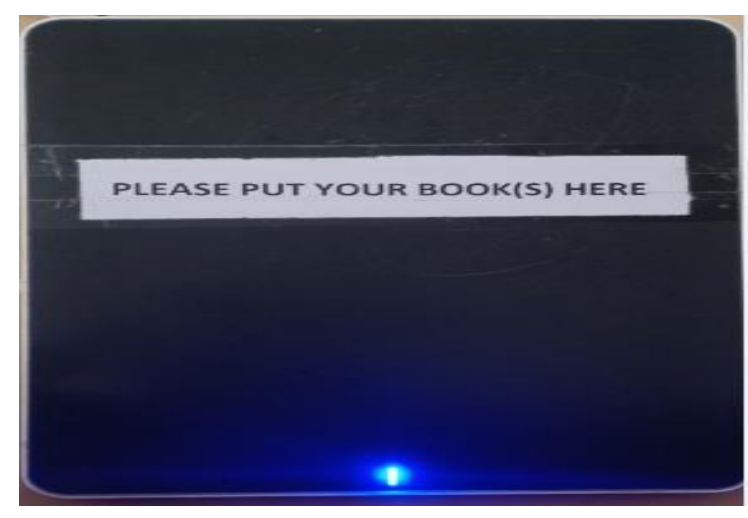

Fig 5: RFID multi-purpose staff station

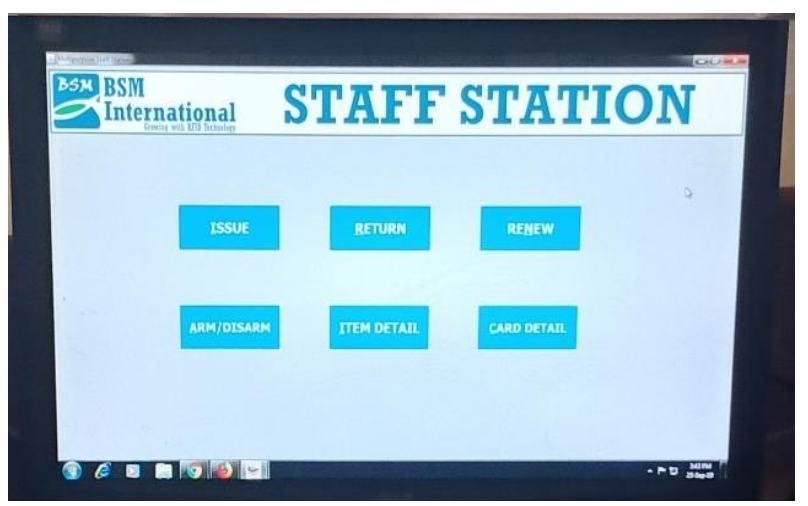

Fig 7: RFID middleware software

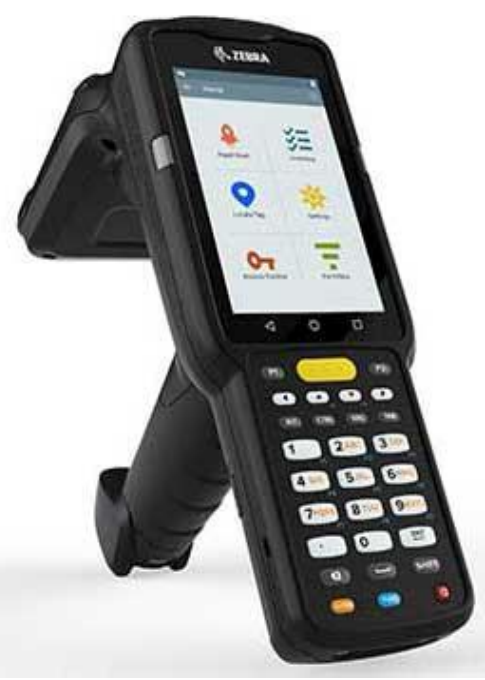

Fig 9: RFID handheld reader 


\section{INSTALLATION PROCESS OF RFID SYSTEM IN ADBU LIBRARY}

\section{Collection of information about RFID system}

This the first and foremost task, before going to install RFID system in the library. Information about RFID system must be collected either from websites, by reading different articles on RFID, books on RFID.

\section{Visit the RFID implemented libraries}

One of the most important aspect is to visit the RFID implemented library to know how the system works, what are the advantages and disadvantages of RFID system in the library, after that, we must compare it with the information which we collected from different sources.

\section{Compare the merits and demerits of RFID systems}

Comparision of the merits and demerits is essential before going to install RFID system in the library, some merits and demerits depend upon the types and size of the library. If it is an ancient library and the collection of the books are very old than it is better to replace the old books with the new books or bind the old books so that RFID tags can easily be pasted on the books.

\section{Contact with vendors}

After all the comparision if you found it satisfactory that time you can contact the RFID vendors for a quotation. A minimum of three quotation is require to compare.

\section{Collect quotations/proposals}

While collecting quotation, ask the vendors to provide all the details like the specification of components, country of origin, price, range of the components, all the terms and conditions, read 
and write capacity of RFID tags and smart cards, warranty period, AMC etc. There should not be any hidden terms and conditions

\section{Compare the quotations}

After collection of all the quotations compare the quotations on the basis of all the criteria, like price, quality of the components, services of the vendor, reading capacity of the tags and smart cards and most importantly AMC of the components. Don't compare the quotations on the basis of price only, there are lots of RFID components in the market available in a low price but these are not durable, so before going for any RFID product please confirm the durability of the product, once you install the product in the library it is not possible to replace the product ever time.

\section{Finalize the quotation}

Finalize the vendor on the basis of the price and other specification of the RFID components, if possible select the local vendor if any so that if any problem occurs at any time they can provide quick services.

\section{Arrange a meeting with the experts and higher authorities of the institution}

After collecting all the quotations from different vendors, a meeting with the experts and the higher authority of the institutions must be conducted. Meeting should include the discussion on the price and the specification of the product and its service quality.

\section{Phase wise selection of RFID components}

It will be best if we purchase the RFID components in two phases, in the first phase the most require RFID components should be purchased. The components are RFID tag, sticker, 
multipurpose staff station, middleware software. And in the second phase, we can go for RFID smart card, card reader, RFID security gate and handheld reader (Optional)

\section{Preparation of purchase order}

After a successful meeting, the librarian or library staff has to prepare a purchase order mentioning the components for purchase in the first phase. The purchase order must contain all the terms and conditions, place of supply the RFID components, stipulated period of installing the software etc.

\section{Design the RFID sticker as per your requirement}

RFID sticker has to be put on the RFID tag in the book, and we can design the cover of the sticker as per our need, it may contain the name of the institution, name of the library and other relevant information.

\section{Install the middleware software and hardware by the vendor}

Middleware software works as a communicator between the RFID hardware and the library management software. Installation has to be done by the vendor. After installing RFID hardware middleware software has to be installed in the server or in a high configured computer. The software has a features of tagging books, activating smart cards, issue and return library books, renew library patrons, check the status of the books, check user details etc.

\section{SIP2 server configuration for connection middleware software with the ILMS-Koha}

After successful installation of RFID hardware and middleware software, it needs to configure SIP2 server of library management software with the RFID middleware software. Assam Don Bosco University is using Koha ILMS, so by logging through Ubuntu terminal, we have configured our SIP2 server. 


\section{Pasting of RFID tags and stickers on the books and other study materials}

The main task begin here is to paste RFID tag and sticker in the books and other study materials, the duration of this work depends on the number of books and other study materials and the number of staffs deployed for the task.

\section{Tagging the books and other study materials through RFID multipurpose staff station}

Tagging of books and other study materials can be done simultaneously with the pasting of RFID tags. Tagging can be done through the multipurpose staff station. We need open the tagging station application and then put the book/study material in which RFID tag has been pasted on the RFID tagging station, after that we have to enter the accession number of the book/study material in the box displayed in the screen, then click on show, it will display the bibliographic information of the book/study material after that we have to click on scan and write one after another. After successful completion of tagging "Item Tagged Successful" message will display on screen.

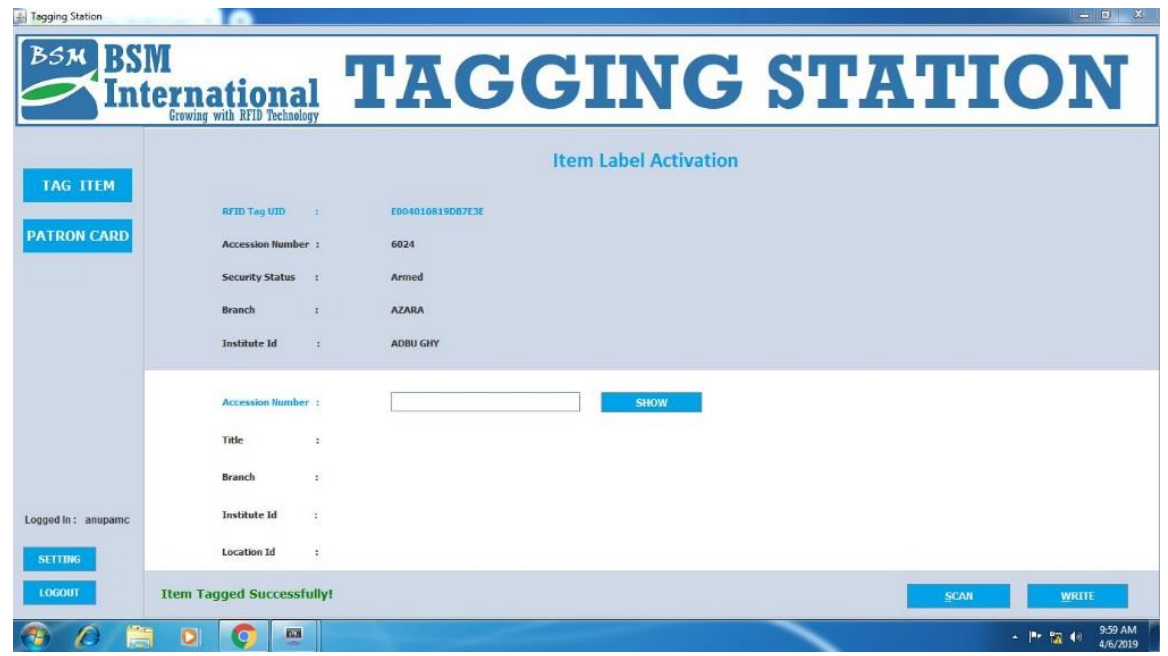

Fig 10: RFID book tagging interface 


\section{Mark the books and other study materials after tagging done successfully}

Final step of tagging is to mark the book/study material with some permanent ink, so that later part when we check the book/study material we can easily identify which book/study material has already been tagged.

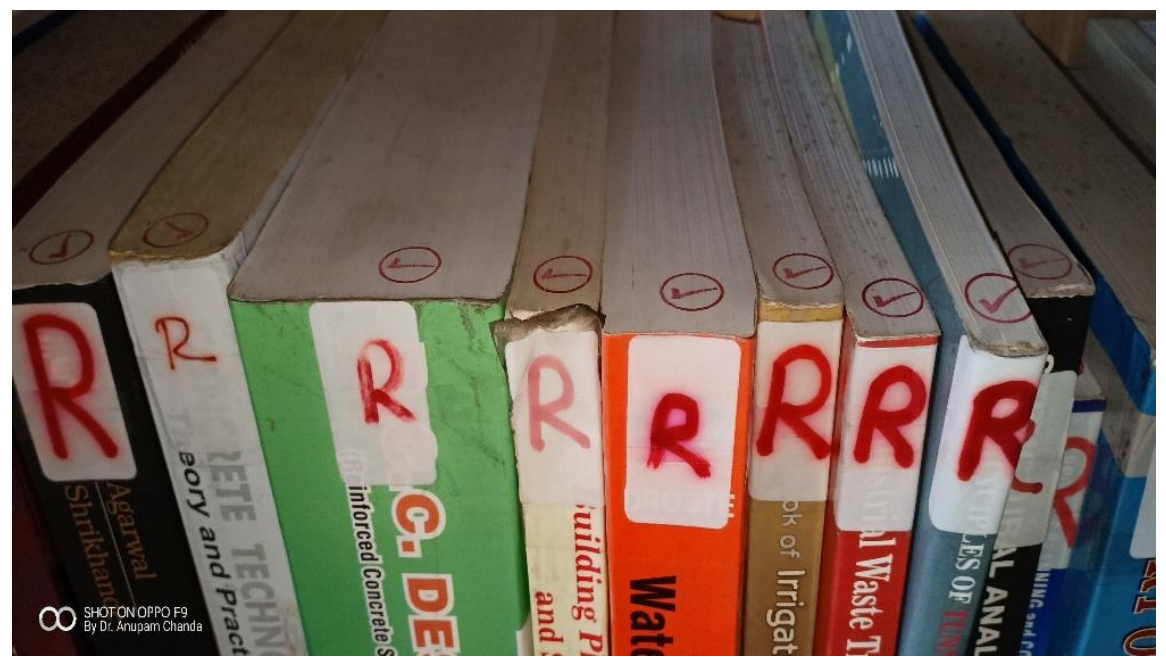

Fig 11: Mark on the books after completion of tagging

\section{Printing and activation of RFID enabled library ID card}

After successful completion of tagging all the library books/study materials, the next step is to print the RFID enabled library ID card and then activate the ID cards through the RFID smart card reader, without ID card books can not be issued to the users. The acticvation process is same like tagging of books. One message "Card Issued Sussessfully" will display on the screes after successful activation of the card. 


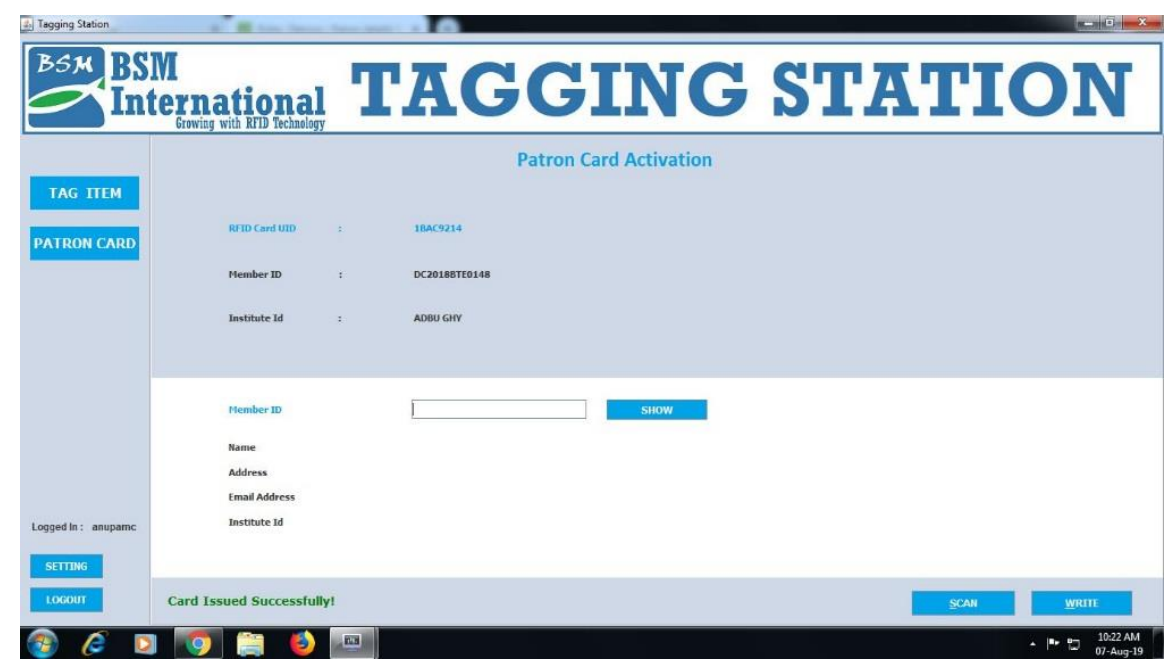

Fig 12: RFID smart card activation interface

\section{Circulation}

Once all the above process is complete, the library can start its circulation through RFID multipurpose staff station or through the self-issue-return kiosk.

\section{Working process RFID system in ADBU library}

In ADBU library we use RFID system for circulation, stock verification and theft detection purpose.

RFID helps to save time with maximum accuracy in circulation counter, users need to put their ID card on the card reader and books on the multipurpose staff station, then the staff seating in the circulation section has open the staff station application (one time) and then have to click on the scan button and the issue button one by one, after that books will automatically be issued to the user and a print slip will automatically generate, there is no need to give print command, we have customized the middleware software in such a way that it will take automatic print command, it also saves the time of the circulation staff and also the user. 
Stock verification through RFID system can be done easily and accurately, with the help of RFID handheld reader we can be done stock verification within a few hours, depends on the collection of the books. ADBU has almost 24000 books in the library. The process is like we need to take a tour with the handheld reader in the book shelves, the reader automatically collect the accession number of ever books available in the shelves, after collection all the data we can export it into an excel file, later we can download the accession register from our library management software and then we can compare both the file. Then we have to download checkout data to compare with the list of accession number which we found absent earlier. After the final comparison we can conclude with the result, the number of missing books in the library, so it will take hardly one day to complete the entire process, means it saves lots of time of the library staffs.

Theft detection is one of the most valuable features of RFID system, if any user takes a book without checkout the book properly, the security gate will automatically detect the book and buzz an alarm, it will help the library staff to identify the user who is taking the books without proper permission. Because of theft, every year the library faces a huge loss, so after the installation of RFID system, the problem has solved.

\section{Benefits of RFID system for the library}

- RFID system in a library reduces the time needed for circulation duties since multiple tags can be read at a time;

- Error-free circulation is one of the essential features of RFID system;

- Patron self-issue/return kiosk can additionally free up staff from the duties in the circulation section; 
- Library staffs may be used more efficiently in other areas including increased face-toface service and increased the number of community programs;

- $\quad$ Theft detection is easy;

- Stock verification can be done quickly with maximum accuracy;

- Searching of library materials can easily be done with the help of RFID hand-held reader.

\section{SUGGESTIONS}

- Before going to install RFID system in the library, the librarian must check the value of the library materials (books), whether these are in good condition or not, if the books are very old and the prices are low then better not to install RFID system in the library. But if you really want to install RFID than you need to replace the old books with the new one preferable with the hard bound books.

- Check the features and the manufacturing country of RFID components before purchasing, ask your vendor to give all the details with the quotation.

- Buy high-quality RFID tags, because once the tags have been pasted on the books it can not easily be replaced. There are many types of RFID tags in the market, so go for highquality tags, which can give at least 1lakh transactions.

- Paste the RFID tags in the middle of the back cover page of the books, so that RFID staff station of self kiosk reader can easily read the tags.

- Buy the RFID components in two-phase: $1^{\text {st }}$ phase- RFID tags, Sticker, Staff Station Middleware software, and in $2^{\text {nd }}$ phase- RFID smart card reader, RFID security gate, RFID hand-held reader (optional). 
- Go with the vendor who can give you quick services, consult with the librarians who has already installed RFID in the libraries.

- Sometimes middleware software may not work and your ILMS may also give problem so always try to take a backup of your data.

- Ask the RFID vendor to provide proper training to the library staffs so that they can manage if any problem occurs.

\section{CONCLUSION}

RFID system brought the revolution in library and information centres, libraries have become a driving force in the development of RFID for the mass market, RFID system is a prevalent system that addresses both the security and library materials tracking needs of a library. Today many libraries are using the technology for the prevention of theft in the library. It is essential to educate library staff and library users about RFID system before implementing it in the library. Signs of Progress in RFID systems continue to yield larger memory capacities, wider reading ranges, and faster processing. The interest in RFID as a solution to improve further the automation and tracking of documents are assembly momentum at an increasing pace, with more libraries joining the trails.

In ADBU library we have completed all the process of installation of RFID hardware and software as well as pasting of tags in the books, tagging, smart card printing and activation of smart cards within 120 days. The whole system is running quite flawlessly in the library. BSM International is providing all the services, and they are the supplier of all the RFID components as well as they are also the service provider. 


\section{REFERENCES}

Erwin, E., \& Kern, C. (2005). Radio Frequency Identification in Libraries. Australasian Public Libraries and Information Services, 18(1), 20-29. Retrieved from https://www.worldcat.org/title/radio-frequency-identification-inlibraries/oclc/4808846412\&referer=brief_results

Pal, N., \& Sharma, A. K. (2017). Implementation of RFID Technology in Library. International Journal of Digital Library Services,7(2), 70-79. Retrieved from http://www.ijodls.in/uploads/3/6/0/3/3603729/8ijodls217.pdf

Shahid, S. M. (2005). Use of RFID Technology in Libraries: a New Approach to Circulation, Tracking, Inventorying, and Security of Library Materials. Library Philosophy and

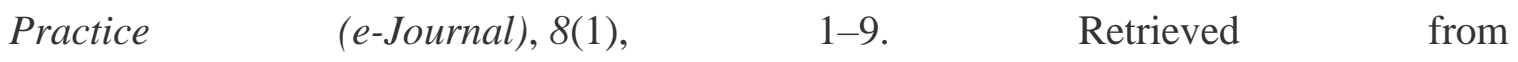
https://digitalcommons.unl.edu/libphilprac/62

Singh, N. K., \& Mahajan, P. (2014). Application of RFID Technology in Libraries. International Journal of Library and Information Studies, 4(2), 1-9. Retrieved from https://www.researchgate.net/publication/272576139_APPLICATION_OF_RFID_TECH NOLOGY_IN_LIBRARIES 